\title{
Solid-state NMR study of bioactive binary borosilicate glasses
}

\author{
Tim W.T. Tsai ${ }^{a}$, Yun Mou ${ }^{a}$, Yao-Hung Tseng ${ }^{a}$, Long Zhang ${ }^{b}$, Jerry C.C. Chan ${ }^{a, *}$ \\ a Department of Chemistry, National Taiwan University, No. 1, Section 4, Roosevelt Road, Taipei, Taiwan, ROC \\ ${ }^{\mathrm{b}}$ Shanghai Institute of Optics and Fine Mechanics, Chinese Academy of Sciences, P.O. Box 800-211, Shanghai 201800, China
}

\section{A R T I C L E I N F O}

\section{Article history:}

Received 15 June 2007

Received in revised form

8 April 2008

Accepted 4 June 2008

Keywords:

A. Glasses

A. Oxides

D. NMR

\begin{abstract}
A B S T R A C T
A series of binary borosilicate glasses prepared by the sol-gel method are shown to be bioactive. Tetraethyl orthosilicate (TEOS) and trimethylborate (TMB) in acidic medium are used to prepare $x \mathrm{~B}_{2} \mathrm{O}_{3} \cdot(1-x) \mathrm{SiO}_{2}$ glass systems for $x=0.045-0.167$. The formation of a layer of apatite-like mineral on the glass surface becomes apparent after soaking in simulated body fluid for $48 \mathrm{~h}$. We have measured the ${ }^{11} \mathrm{~B}-{ }^{11} \mathrm{~B}$ homonuclear second moments of the borosilicate glasses and inferred that no macroscopic phase separation occurred in our glasses. The ${ }^{11} \mathrm{~B}$ chemical shift data also show that the formation of clustered boroxol rings is negligible in our glass system. Although the bioactivity of our borosilicate glasses is less than that of $\mathrm{CaO}-\mathrm{SiO}_{2}$ sol-gel glasses, these simple binary systems could be taken as reference glass systems for the search of new bioactive borosilicate glasses.
\end{abstract}

(c) 2008 Elsevier Ltd. All rights reserved.

\section{Introduction}

Bioactive glass-ceramic materials have been widely investigated in recent years [1-3]. Glasses that are potential implant materials in the human body must exhibit certain solubility to allow the necessary reactions to take place between the living tissues and the glass surface. In general, the dissolution of a glass involves the processes of leaching and network dissolution. Bioactive glasses prepared by the melt-quench method usually contain $<60 \% \mathrm{SiO}_{2}$ to maintain sufficient solubility. On the other hand, the sol-gel technique has significantly increased the territory of glass compositions exhibiting bioactivity [4-8]. Because tetrahedral or trigonal boron species can enhance the mechanical strength of a glass system, it is of interest to investigate the effect of the boron content on the bioactivity of silicate glasses. Recently, $\mathrm{B}_{2} \mathrm{O}_{3}$ has been introduced to bioactive silicate glasses as the second network former in order to tailor the glass dissolution rate $[9,10]$. The bioactive glasses or glass ceramics containing considerable amount of boron content are basically limited to the system of $\mathrm{CaO}-\mathrm{Na}_{2} \mathrm{O}-\mathrm{SiO}_{2}-\mathrm{B}_{2} \mathrm{O}_{3}$ prepared by the melt-quench method [9,10]. In this study, we attempt to show that it is possible to prepare $\mathrm{B}_{2} \mathrm{O}_{3}-\mathrm{SiO}_{2}$ glasses with significant bioactivity by the sol-gel method. Tetraethyl orthosilicate (TEOS) and trimethylborate (TMB) in acidic medium are used to prepare $x \mathrm{~B}_{2} \mathrm{O}_{3} \cdot(1-x) \mathrm{SiO}_{2}$ glasses for $x=0.045-0.167$. We have characterized the ${ }^{11} \mathrm{~B}-{ }^{11} \mathrm{~B}$ homonuclear second moments of the borosilicate glasses by monitoring the ${ }^{11} \mathrm{~B}$ spin-echo inten-

\footnotetext{
* Corresponding author. Tel.: +8862 3366 2994; fax: +886223636359.

E-mail address: chanjcc@ntu.edu.tw (J.C.C. Chan).
}

sities as a function of the inter-pulse delay. The comparison with the data obtained for vitreous $\mathrm{B}_{2} \mathrm{O}_{3}$ shows that there is no macroscopic phase separation occurred in our glasses. The ${ }^{11} \mathrm{~B}$ chemical shift data also show that the formation of clustered boroxol rings is negligible in our glass systems. Although the bioactivity of our borosilicate glasses is less than that of $\mathrm{CaO}-\mathrm{SiO}_{2}$ sol-gel glasses, these simple binary systems could be taken as reference glass systems to formulate structure-based principles for the search of new bioactive glasses.

\section{Experimental}

\subsection{Sample preparation}

All the chemicals were obtained from Acros and used as received. The desired batches of the glasses were prepared by mixing TEOS and TMB in water-ethanol mixture. Appropriate amount of TMB was added into $50 \mathrm{~mL}$ ethanol, which was acidified by $\mathrm{HCl}(1.5 \mathrm{~mL}, 12 \mathrm{~N})$ and acetic acid $(1.5 \mathrm{~mL})$. After adding TEOS, the mixture was stirred vigorously for $15 \mathrm{~min}$. Water was then added and the mixture was further agitated for another $15 \mathrm{~min}$. The molar ratios of TEOS to water and to ethanol were kept at $1: 16$ and $1: 11.5$, respectively. The molar ratio of TEOS to TMB was varied from 1:0.1 to 1:0.5. The sol was hermetically sealed in a polypropylene bottle and placed in an oven for aging. The aged samples were then dried in the oven. The dried gels were stabilized at high temperature to form glasses. The temperature schedules for aging, drying and stabilization are summarized in 
Table 1

Temperature schedule for the glass preparation

\begin{tabular}{cccc}
\hline Stage & Ramp $\left({ }^{\circ} \mathrm{C} / \mathrm{min}\right)$ & Destination temp $\left({ }^{\circ} \mathrm{C}\right)$ & Duration $(\mathrm{h})$ \\
\hline Aging & & & 5 \\
1 & 0.12 & 60 & 50 \\
2 & 0 & 25 & 5 \\
3 & -0.12 & & \\
& & 60 & 5 \\
Drying & 0.12 & 150 & 20 \\
1 & 0.075 & 180 & 20 \\
2 & 0.025 & 180 & 12 \\
3 & 0 & 25 & 1 \\
4 & -2.6 & & 1.5 \\
5 & & 105 & 3.7 \\
Stabilization & 0.88 & 160 & 11.3 \\
1 & 0.25 & 500 & 72 \\
2 & 0.5 & 700 & 1 \\
3 & 0.046 & 700 & 6 \\
4 & 0 & 25 & \\
5 & -1.88 & & \\
6 & & &
\end{tabular}

Table 1 . Approximately $4 \mathrm{~g}$ of borosilicate glass was prepared for each batch. The glasses were then grinded into powder form.

Segments of $200 \mathrm{mg}$ of the glasses were soaked in $500 \mathrm{~mL}$ of simulated body fluid (SBF), which was prepared by dissolving $\mathrm{MgCl}_{2} \cdot 6 \mathrm{H}_{2} \mathrm{O}(1.50 \mathrm{mM}), \mathrm{NaCl}(136.9 \mathrm{mM}), \mathrm{CaCl}_{2}(3.76 \mathrm{mM})$, $\mathrm{NaHCO}_{3}(4.18 \mathrm{mM}), \mathrm{K}_{2} \mathrm{HPO}_{4} \cdot 3 \mathrm{H}_{2} \mathrm{O}(1.00 \mathrm{mM}), \mathrm{KCl}(3.00 \mathrm{mM})$ and $\mathrm{Na}_{2} \mathrm{SO}_{4}(0.50 \mathrm{mM})$ in deionized water sequentially [11]. Sodium azide $(0.01 \% \mathrm{w} / \mathrm{w})$ was added to suppress bacterial growth. The solution was buffered at 7.4 by tris(hydroxymethyl)aminomethane $(53.82 \mathrm{mM})$ and $\mathrm{HCl}(43.97 \mathrm{mM})$. The freshly prepared SBF solution was filtered through a $1 \mu \mathrm{m}$ filter before use. The glass samples in SBF were incubated in an orbital shaker under $175 \mathrm{rpm}$ at $37^{\circ} \mathrm{C}$ for various soaking periods, viz. 48, 64 and $91 \mathrm{~h}$. The glasses were collected by filtration through a $1 \mu \mathrm{m}$ filter and subsequently rinsed by deionized water, ethanol and acetone. All the samples were dried under reduced pressure for 2 days before measurements.

\subsection{Sample characterization}

X-ray diffraction (XRD) analysis was performed on a Philips X'Pert diffractometer, using $\mathrm{Cu}-\mathrm{K} \alpha$ radiation $(\lambda=1.5418 \AA)$. The field emission scanning electron microscopy (FE-SEM) and the energy dispersive X-ray (EDX) analysis were done on a JEOL-JSM$6700 \mathrm{~F}$ field emission scanning electron microscope (operated at $10 \mathrm{kV}$ ) equipped with an Oxford INCA energy dispersive X-ray spectrometer. Raman measurements were conducted using a JOBIN YVON HORIBA-HR800 instrument, operating with a Nd/YAG laser at $532 \mathrm{~nm}$. Fourier transform infrared (FT-IR) spectra were collected using a Magna-IR 550 spectrometer (series II), in the range of $400-4000 \mathrm{~cm}^{-1}$. All NMR experiments were carried out at ${ }^{11} \mathrm{~B}$ frequencies of 96.3 and $160.4 \mathrm{MHz}$, respectively, on a Bruker DSX300 and DSX500 NMR spectrometers equipped with a specially designed commercial $4-\mathrm{mm}$ probe (without any significant ${ }^{11} \mathrm{~B}$ background signal). The sample $(40 \mathrm{mg})$ was confined to the middle region of the rotor volume using Teflon spacers. ${ }^{11} \mathrm{~B}$ chemical shifts were externally referenced to $\mathrm{BF}_{3} \cdot \mathrm{Et}_{2} \mathrm{O}$, which was sealed in a glass ampoule. Spin-lattice relaxation times $\left(T_{1}\right)$ were determined by the saturation-recovery technique. Magicangle spinning (MAS) spectra were measured by one-pulse excitation at a spin rate of $10 \mathrm{kHz}$ without proton decoupling. The pulse flip angle was set to $15^{\circ}$, the pre-acquisition delay to $7 \mu \mathrm{s}$ and the $B_{1}$ field to $60 \mathrm{kHz}$. A total of 120 transients were accumulated for each spectrum and the recycle delay was set to $5 \mathrm{~s}$. The line shape deconvolution was carried out by the package DMfit2003 [12]. ${ }^{11} \mathrm{~B}$ spin-echo measurements were carried out under static condition at $11.74 \mathrm{~T}(160.4 \mathrm{MHz})$. The selective $\pi / 2$ pulse was set to $4.2 \mu \mathrm{s}$. This condition corresponds to the selective excitation of the central transition, as was ascertained by the observation of strictly sinusoidal nutation profile.

\section{Results}

\subsection{Glass structure}

A series of borosilicate glasses were prepared with different molar percentages of $\mathrm{B}_{2} \mathrm{O}_{3}$, viz. $4.5,12.5$ and $16.7 \mathrm{~mol} \%$. All the glass samples will be henceforth labeled based on their percentage contents of $\mathrm{B}_{2} \mathrm{O}_{3}$. XRD measurements show that no crystalline phases are present in our glass samples. Fig. 1 shows the ${ }^{11} \mathrm{~B}$ MAS spectra measured for the glass samples at 7.05 and $11.74 \mathrm{~T}$, which exhibit typical features arising from the second-order quadrupolar broadening [13]. The NMR data summarized in Table 2 were determined by the line shape deconvolution and the spectra at two fields were simulated by the same set of NMR parameters for each sample. The fits are not perfect as commonly observed for glassy materials because each of the NMR parameters has a distribution about a mean value [14]. Clearly, there are no tetrahedral boron sites found and this observation is consistent with the notion that network modifiers such as alkalior alkaline oxide are required to convert $\mathrm{BO}_{3}$ units to $\mathrm{BO}_{4}^{-}$units. For each of our samples, there is only one major boron species which can be identified as $\mathrm{BO}_{3 / 2}$ because the asymmetry parameters $\eta_{\mathrm{Q}}$ determined are significantly less than $0.5[14,15]$. Recently, it has been reported that the ${ }^{11} \mathrm{~B}$ chemical shifts of the boroxol rings and the non-ring $\mathrm{BO}_{3 / 2}$ units in a series of borosilicate glasses are in the range of 15.7-17.4 and 11.0-12.5 ppm, respectively, in which the boron species become more deshielded as the boron content increases from 28 to $100 \mathrm{~mol} \%$ [16]. Also, the ${ }^{11} \mathrm{~B}$ chemical shift of $\mathrm{BO}_{3 / 2}$ unit connected to three silicon atoms was found to be $9.7 \mathrm{ppm}$ [17]. The isotropic ${ }^{11} \mathrm{~B}$ chemical shifts observed for our glasses are in the range of 12.8-13.3 ppm. Consequently, we can rule out the existence of the $\mathrm{B}-(\mathrm{OSi}-)_{3}$ species in our glasses. The formation of a network of inter-connected boroxol rings in our glasses is also unlikely. In an earlier report, however, clustered boroxol rings were found in a borosilicate glass system containing $5 \mathrm{~mol} \%$ of $\mathrm{B}_{2} \mathrm{O}_{3}$, which was prepared by sol-gel method in alkaline medium [18]. It was estimated that only $66 \%$ of the $\mathrm{BO}_{3 / 2}$ units mixed statistically with silica tetrahedra and the rest formed a borate network, resulting in the formation of boroxol rings [18]. Apparently, a more homogeneous glass matrix can be obtained in acidic medium as demonstrated in this work.

To probe for the connectivities among the boron units, we measured the ${ }^{11} \mathrm{~B}-{ }^{11} \mathrm{~B}$ van Vleck's second moments of our glass samples by spin-echo decay spectroscopy. A detailed discussion of this approach is well documented in the literature [19-21]. In brief, the normalized echo intensity, $I(t) / I_{0}$, is measured as a function of the evolution time $\left(2 t_{1}\right)$. For a multi-spin system, a Gaussian decay is expected in the limit of short dipolar evolution times $\left(2 t_{1}<200 \mu \mathrm{s}\right)$ :

$\frac{I\left(2 t_{1}\right)}{I_{0}}=\exp \left[-\frac{M_{2}}{2}\left(2 t_{1}\right)^{2}\right]$

With reference to the results shown in Fig. 2, the $\mathrm{BO}_{3 / 2}$ units have a strong tendency to form B-O-B linkages. Nevertheless, because the extracted second moments of the glasses are considerably less than that determined for the vitreous $\mathrm{B}_{2} \mathrm{O}_{3}$ 
11.74 Tesla
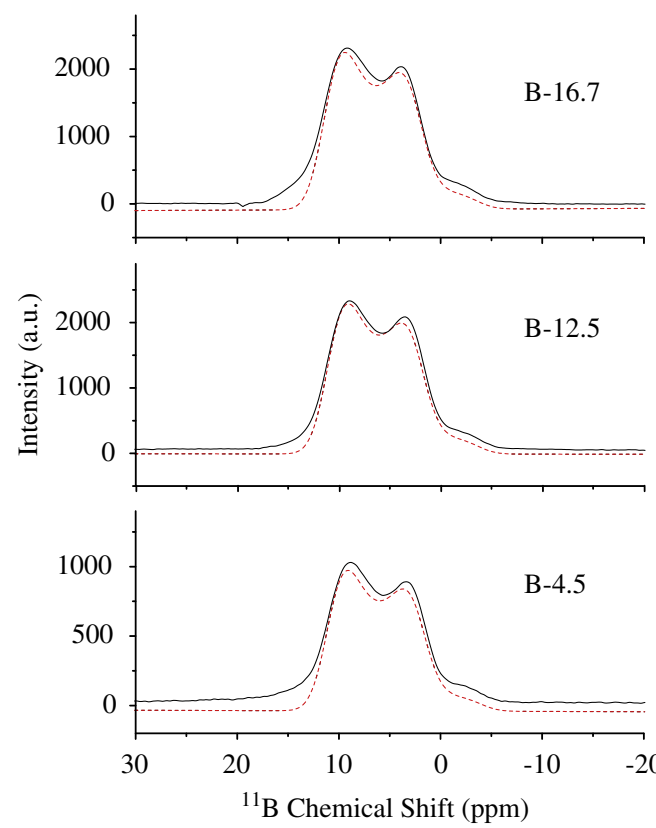

7.05 Tesla

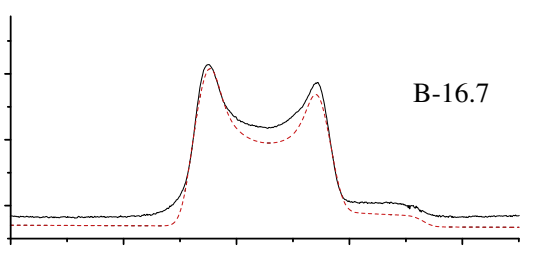

B-12.5

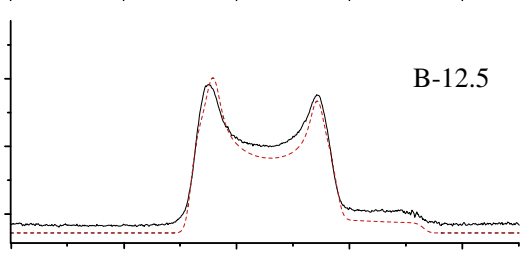

B-4.5

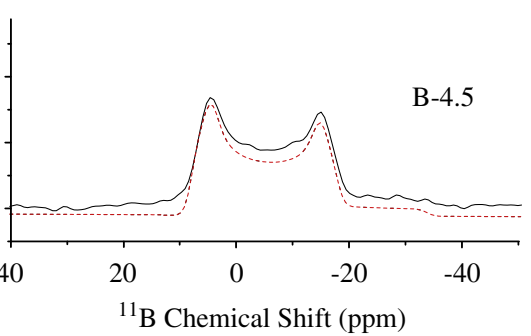

Fig. 1. ${ }^{11} \mathrm{~B}$ MAS spectra of the glass samples measured at 7.05 and $11.74 \mathrm{~T}$. The solid and dashed traces correspond to the experimental and simulation spectra, respectively.

Table 2

NMR parameters extracted by line shape deconvolution of ${ }^{11} \mathrm{~B}$ MAS spectra ${ }^{\mathrm{a}}$

\begin{tabular}{llll}
\hline Sample & $\delta(\mathrm{ppm})$ & $\eta_{\mathrm{Q}}$ & $C_{\mathrm{Q}}(\mathrm{MHz})$ \\
\hline B-16.7 & $13.3 \pm 0.1$ & $0.14 \pm 0.01$ & $2.62 \pm 0.02$ \\
B-12.5 & $12.8 \pm 0.3$ & $0.15 \pm 0.01$ & $2.61 \pm 0.03$ \\
B-4.5 & $12.8 \pm 0.1$ & $0.13 \pm 0.01$ & $2.63 \pm 0.03$ \\
\hline
\end{tabular}

${ }^{\mathrm{a}}$ The ${ }^{11} \mathrm{~B}$ spin-lattice relaxation time was found to be c.a. $1.7 \mathrm{~s}$.

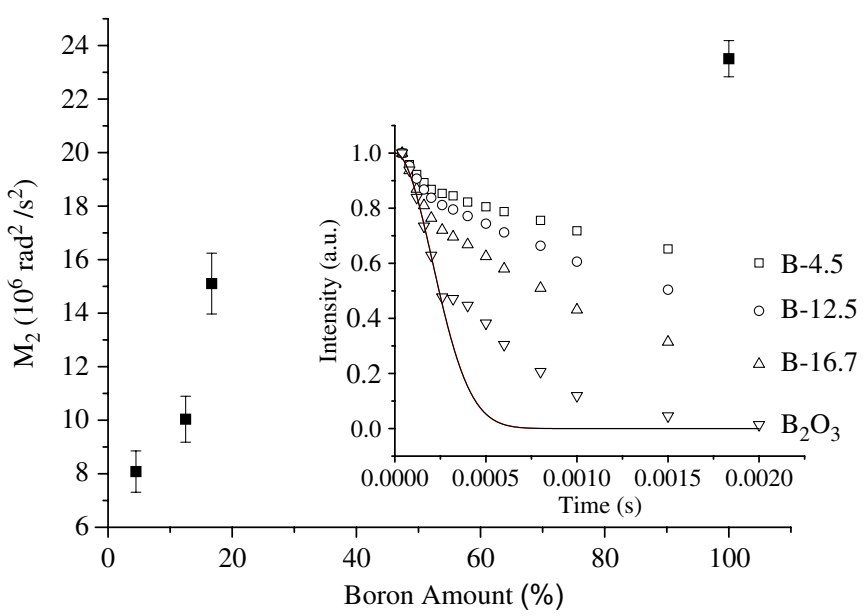

Fig. 2. Dependence of the ${ }^{11} \mathrm{~B}-{ }^{11} \mathrm{~B}$ second moments on the boron content in mol \%. The inset shows the raw data of the spin-echo measurements. The solid line is the Gaussian-decay curve fitted to the vitreous $\mathrm{B}_{2} \mathrm{O}_{3}$ data in the limit of short dipolar evolution times $\left(2 t_{1}<200 \mu \mathrm{s}\right)$.

sample, we conclude that there is no macroscopic phase separation occurred in our glasses. In principle, one may also employ other sophisticated NMR techniques such as double-

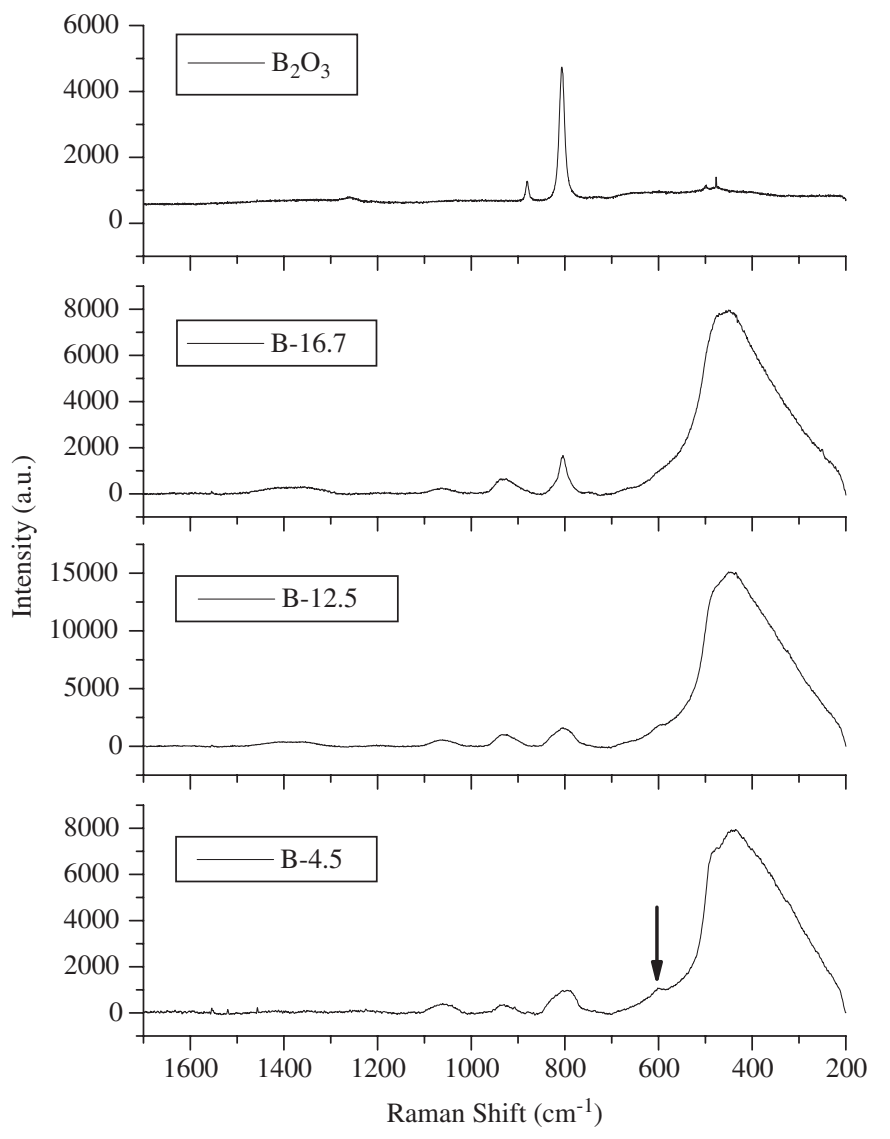

Fig. 3. Raman spectra of the glass samples. The small peak at $600 \mathrm{~cm}^{-1}$ (marked by an arrow) is attributed to $\mathrm{Si}-\mathrm{O}-\mathrm{B}$ linkages.

resonance methods to investigate the medium-range order of the boron units [22] but such a detailed NMR study is beyond the scope of this work. 
Fig. 3 shows the Raman spectra measured for our glasses and the vitreous $\mathrm{B}_{2} \mathrm{O}_{3}$ sample. The intensity of the band at $808 \mathrm{~cm}^{-1}$ increases with the percentage of $\mathrm{B}_{2} \mathrm{O}_{3}$. In comparison with the spectrum measured for pure $\mathrm{B}_{2} \mathrm{O}_{3}$, this band can be attributed to the vibrations of the $\mathrm{B}-\mathrm{O}-\mathrm{B}$ linkages [23-25]. The absence of a peak at $795 \mathrm{~cm}^{-1}$ confirms that there is no $\mathrm{BO}_{4}$ unit present in our glasses [26]. A small peak at $600 \mathrm{~cm}^{-1}$ is attributed to $\mathrm{Si}-\mathrm{O}-\mathrm{B}$ linkages [27]. The most intense band centered at $450 \mathrm{~cm}^{-1}$ is assigned to the vibrations of the $\mathrm{Si}-\mathrm{O}-\mathrm{Si}$ bonds [24,27]. In the literature, the weak bands at around 950 and $1090 \mathrm{~cm}^{-1}$ were assigned to the stretching $\mathrm{Si}-\mathrm{O}$ vibration in $\mathrm{Q}^{2}$ and $\mathrm{Q}^{3}$ species [27]. However, ${ }^{29} \mathrm{Si}$ NMR data show that $\mathrm{SiO}_{4 / 2}$ units are the major species in our samples and the amount of $Q^{2}$ and $Q^{3}$ species, if any, are very low (Supporting Information). We note in passing that ${ }^{17} \mathrm{O}$ NMR has been shown to be an effective method to probe and quantify the nature of bridging oxygen species in borosilicate glasses $[28,29]$.

\subsection{Bioactivity}

To examine whether our borosilicate glasses have bioactivity, we follow the standard practice by soaking the samples in SBF for different periods [2], viz. 48, 64 and $91 \mathrm{~h}$. Fig. 4 shows the SEM images of the B-12.5 sample before and after soaking in SBF for $48 \mathrm{~h}$. The SEM results show that the minerals deposited on the glass surface have morphologies similar to the crystal habits of apatites formed on bioactive glasses. The average $\mathrm{Ca} / \mathrm{P}$ ratio is determined to be 1.53 by EDX analysis, which is similar to what we expected for apatites formed on bioactive glass surface [30]. Additional SEM images were obtained for samples with longer soaking times and we found that more minerals were deposited as the soaking time increased. To identify the minerals formed on the glass surface, the XRD patterns of our sample series were measured. The results obtained for B-12.5 are shown in Fig. 5. After soaking the sample for $48 \mathrm{~h}$, two broad peaks at $2 \theta$ equal to $26^{\circ}$ and $32^{\circ}$ becomes apparent, suggesting the incipient formation of a low crystallinity apatite-like phase on the glass surface [31]. As the soaking time increases further to $91 \mathrm{~h}$, the peak intensities become more prominent. However, the resolution of the diffraction pattern remains poor, which could be attributed to the poor crystallinity and/or the nanosize of the crystallites. Similar results were obtained for other glasses with different boron contents (data not shown). As a control experiment, a powder sample of Pyrex glass was soaked in SBF for $91 \mathrm{~h}$ and no XRD diffraction peaks were observed.

Fig. 6 shows the FT-IR data measured for the B-12.5 sample with different SBF soaking periods. The absorption peaks observed in the $64 \mathrm{~h}$ sample in the regions of 560 and $600 \mathrm{~cm}^{-1}$ are assigned to the $\mathrm{P}-\mathrm{O}$ bending mode [32-34], which becomes more intense as the soaking time increased to $91 \mathrm{~h}$. The small peak at $875 \mathrm{~cm}^{-1}$ is assigned to the $\mathrm{CO}$ stretching of $\mathrm{CO}_{3}^{2-}$ ions $[8,35]$. This CO stretching peak was also observed in other studies $[8,34]$.

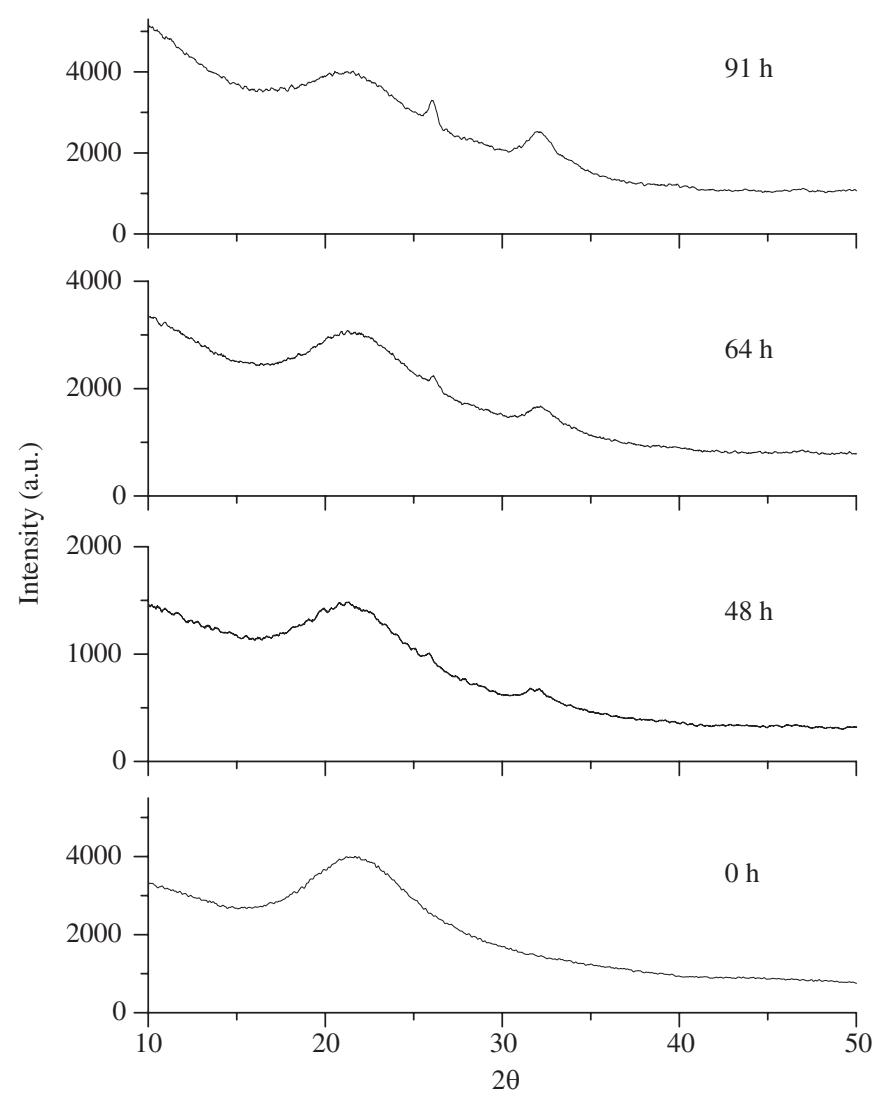

Fig. 5. XRD patterns for the B-12.5 sample soaked in SBF for different periods.
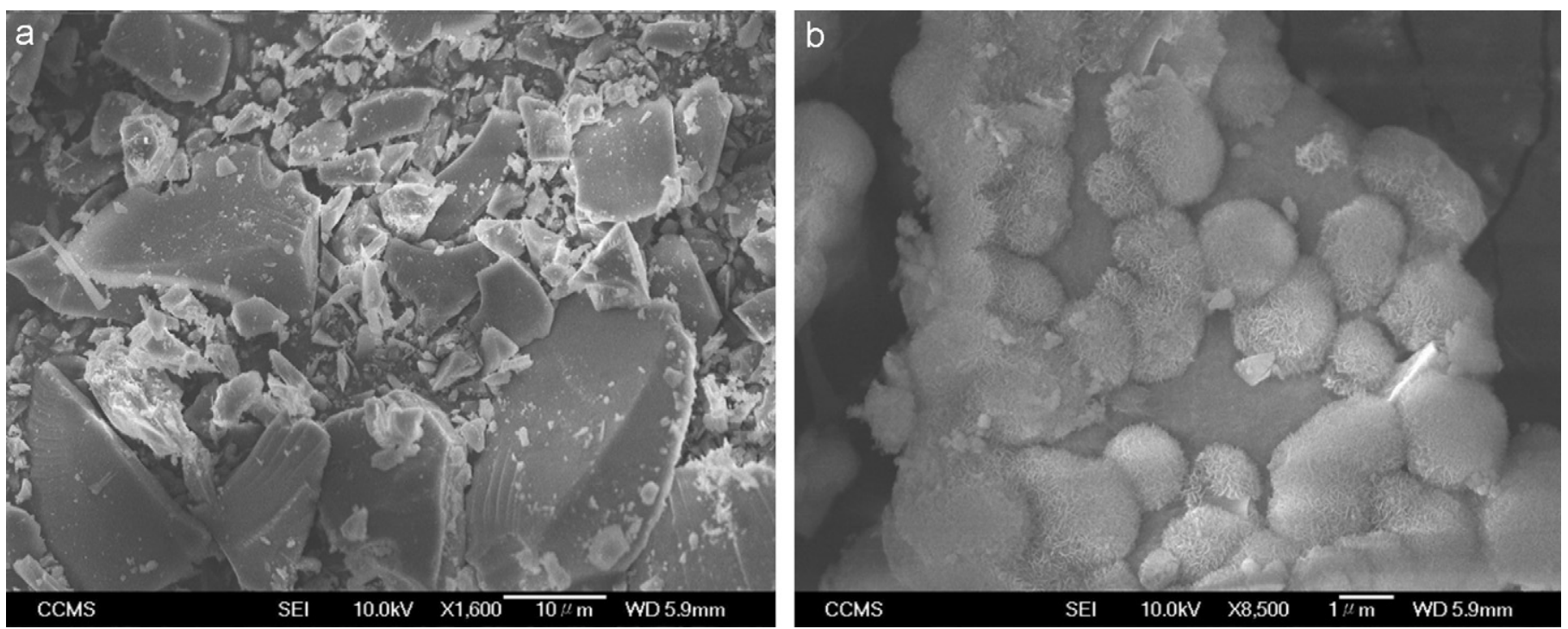

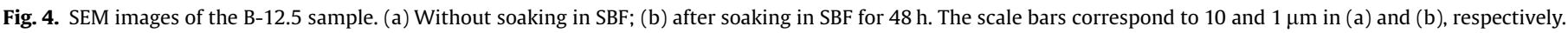




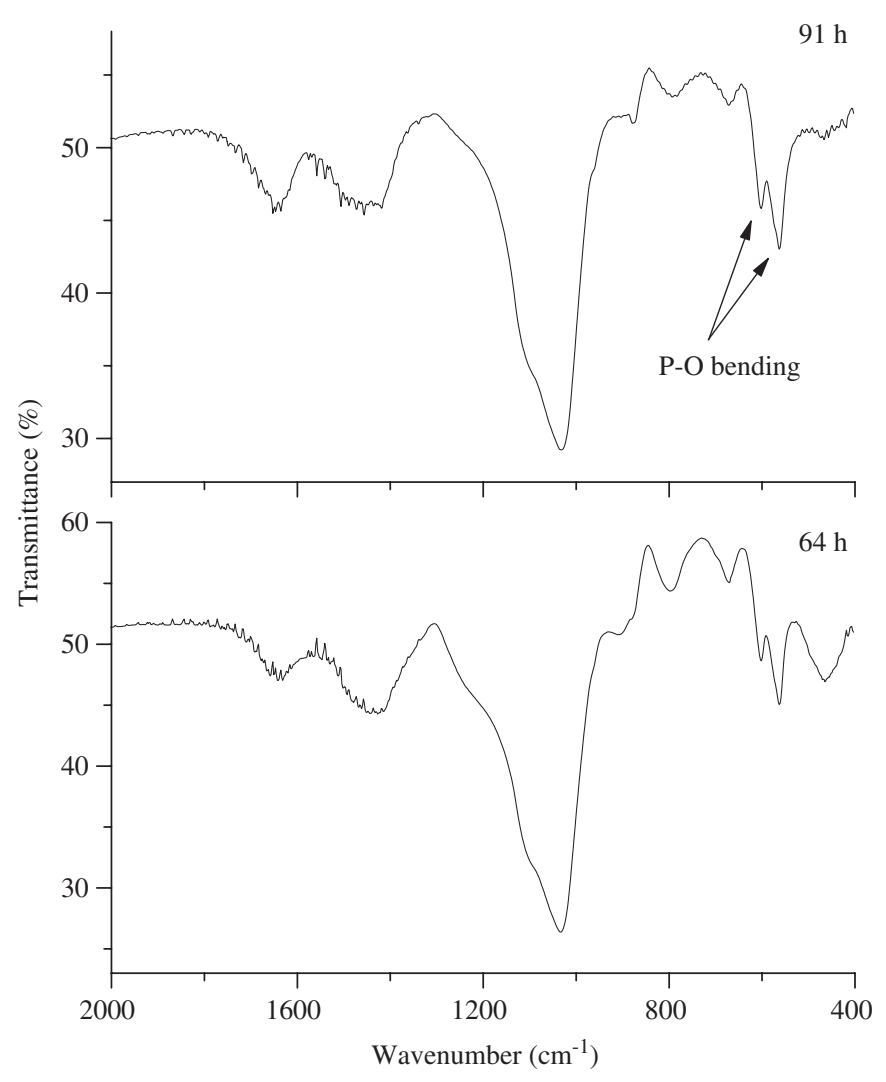

Fig. 6. FT-IR spectra of the B-12.5 sample soaked in SBF for different periods.

\section{Discussion}

For the sol-gel preparation of borosilicate glasses, it is important to avoid macroscopic phase separation. The key is to select suitable reaction conditions so that the hydrolysis rates of the silicon and boron precursors are similar. Although TEOS is a common precursor to synthesize silicate materials, there are many different boron precursors reported for the sol-gel preparation of boron-containing glasses [36-41]. Typical examples are boron oxide and boron alkoxides, $\mathrm{B}(\mathrm{OR})_{3}$. Some years ago, it had been reported that no $\mathrm{B}-\mathrm{O}-\mathrm{Si}$ bonds would exist in the gels prepared by tetrafunctional silicon alkoxides and trialkylborates because of the high hydrolysis rate of $\mathrm{B}-\mathrm{O}-\mathrm{Si}$ linkages $[42,43]$. Consequently, modified silicon alkoxide $\mathrm{R}^{\prime}-\mathrm{Si}(\mathrm{OR})_{3}$ are developed to prepare the $\mathrm{SiO}_{2}-\mathrm{B}_{2} \mathrm{O}_{3}$ gel, in which the $\mathrm{BO}_{3}$ units are homogeneously dispersed in the $\mathrm{SiO}_{2}$ network via $\mathrm{B}-\mathrm{O}-\mathrm{Si}$ bonds [44]. Nevertheless, in this study we demonstrate that a mixture of TMB and TEOS can be used to prepare considerable B-O-Si linkages when the reaction conditions are carefully optimized. Although our NMR instrument does not allow us to perform any ${ }^{29} \mathrm{Si}-{ }^{11} \mathrm{~B}$ double resonance experiment to directly probe the formation of $\mathrm{B}-\mathrm{O}-\mathrm{Si}$ linkages, the ${ }^{11} \mathrm{~B}$ NMR data and the Raman results provide supporting evidence for their existence.

The bioactivity of our borosilicate glasses is unequivocally demonstrated in the SBF soaking experiments. Additional ${ }^{31} \mathrm{P}$ MAS NMR experiments (Supporting Information) show that the amount of phosphate material deposited on the surface of our borosilicate glasses is less than that on the $\mathrm{CaO}(30 \%)-\mathrm{SiO}_{2}(70 \%)$ gel glass, which requires an SBF soaking time of $12 \mathrm{~h}$ only for the formation of an apatite-like phase on the surface [30]. In view of the significantly longer incubation time required for the incipient formation of apatite-like minerals, the bioactivity of our borosilicate glasses is considerably less than those of $\mathrm{Na}_{2} \mathrm{O}-\mathrm{SiO}_{2}$ and $\mathrm{CaO}-\mathrm{SiO}_{2}$ sol-gel glasses. This observation is consistent with the notion that the leaching process of alkali or alkaline-earth ions will induce the formation of apatite-like mineral on the glass surface [1,2].

\section{Conclusion}

In this work we have prepared a series of binary borosilicate glasses by the sol-gel method. The ${ }^{11} \mathrm{~B}$ NMR data show that the formation of clustered boroxol rings is negligible in our glass system. The bioactivity of our borosilicate glasses is unequivocally demonstrated in the SBF soaking experiments. The formation of a layer of apatite-like mineral on the glass surface becomes apparent after soaking in SBF for $48 \mathrm{~h}$.

\section{Acknowledgments}

This work was supported by the National Science Council (Taiwan, R.O.C.). L.Z. thanks the financial support from Shanghai Pujiang program. T.W.T.T. acknowledges an undergraduate stipend from NSC and the traveling support from the internship program of the NRW Graduate School of Chemistry. We thank Professor Hellmut Eckert for his generous support. The NMR measurements at $11.74 \mathrm{~T}$ were carried out at the University of Münster Solid State NMR facility supported by the Ministerium für Wissenschaft und Forschung Nordrhein-Westfälen.

\section{Appendix A. Supporting information}

Supplementary data associated with this article can be found in the online version at doi:10.1016/j.jpcs.2008.06.004.

\section{References}

[1] L.L. Hench, J. Am. Ceram. Soc. 74 (1991) 1487-1510.

[2] L.L. Hench, J.K. West, Life Chem. Rep. 13 (1996) 187-241.

[3] L.L. Hench, I.D. Xynos, J.M. Polak, J. Biomater. Sci.-Polym. Ed. 15 (2004) $543-562$.

[4] J. Zhong, D.C. Greenspan, J. Biomed. Mater. Res. 53 (2000) 694-701.

[5] P. Li, K. Nakanishi, T. Kokubo, K. de Groot, Biomaterials 14 (1993) 963-968.

[6] P.J. Li, C. Ohtsuki, T. Kokubo, K. Nakanishi, N. Soga, T. Nakamura, T. Yamamuro, J. Am. Ceram. Soc. 75 (1992) 2094-2097.

[7] M.M. Pereira, A.E. Clark, L.L. Hench, J. Am. Ceram. Soc. 78 (1995) 2463-2468.

[8] P. Sepulveda, J.R. Jones, L.L. Hench, J. Biomed. Mater. Res. 61 (2002) 301-311.

[9] S.C. Mojumdar, J. Kozankova, J. Chocholousek, J. Majling, V. Nemecek, J. Therm. Anal. Calorim. 78 (2004) 145-152.

[10] H.S. Ryu, J.K. Lee, J.H. Seo, H. Kim, K.S. Hong, D.J. Kim, J.H. Lee, D.H. Lee, B.S Chang, C.K. Lee, S.S. Chung, J. Biomed. Mater. Res. Part A 68A (2004) 79-89.

[11] T. Kokubo, H. Kushitani, S. Sakka, T. Kitsugi, T. Yamamuro, J. Am. Ceram. Soc. 78 (1990) 2463-2468.

[12] B. Alonso, I. Klur, D. Massiot, Chem. Commun. (2002) 804-805.

[13] D. Freude, J. Haase, Quadrupole effects in solid-state nuclear magnetic resonance, in: P.F. Diehl, E. Gunther, H. Kosfeld, R. Seelig (Eds.), NMR Basic Principles and Progress, vol. 29, 1993, pp. 1-90.

[14] L. Züchner, J.C.C. Chan, W. Müller-Warmuth, H. Eckert, J. Phys. Chem. B 102 (1998) 4495-4506.

[15] H.M. Kriz, P.J. Bray, J. Magn. Reson. 4 (1971) 76-84.

[16] L. van Wüllen, G. Schwering, Solid State Nucl. Magn. Reson. 21 (2002) 134-144.

[17] C. Fild, H. Eckert, H. Koller, Angew. Chem. Int. Ed. Engl. 37 (1998) 2505-2507.

[18] L. van Wüllen, W. Müller-Warmuth, D. Papageorgiou, H.J. Pentinghaus, J. NonCryst. Solids 171 (1994) 53-67.

[19] J.D. Epping, W. Strojek, H. Eckert, Phys. Chem. Chem. Phys. 7 (2005) 2384-2389.

[20] J.W. Zwanziger, J.C. McLaughlin, S.L. Tagg, Phys. Rev. B 56 (1997) 5243-5249.

[21] J. Haase, E. Oldfield, J. Magn. Reson. Ser. A 104 (1993) 1-9.

[22] P.M. Aguiar, S. Kroeker, Solid State Nucl. Magn. Reson. 27 (2005) 10-15.

[23] A.M. Zahra, C.Y. Zahra, B. Piriou, J. Non-Cryst. Solids 155 (1993) 45-55.

[24] T. Furukawa, W.B. White, J. Mater. Sci. 16 (1981) 2689-2700.

[25] R.E. Youngman, J.W. Zwanziger, J. Phys. Chem. 100 (1996) 16720-16728.

[26] D. Chen, H. Miyoshi, H. Masui, T. Akai, T. Yazawa, J. Non-Cryst. Solids 345-46 (2004) 104-107. 
[27] N. Ollier, T. Charpentier, B. Boizot, G. Wallez, D. Ghaleb, J. Non-Cryst. Solids 341 (2004) 26-34.

[28] L.S. Du, J.F. Stebbins, J. Phys. Chem. B 107 (2003) 10063-10076.

[29] S.K. Lee, C.B. Musgrave, P.D. Zhao, J.F. Stebbins, J. Phys. Chem. B 105 (2001) $12583-12595$.

[30] K.S.K. Lin, Y.H. Tseng, Y. Mou, Y.C. Hsu, C.M. Yang, J.C.C. Chan, Chem. Mater. 17 (2005) 4493-4501.

[31] M. Vallet-Regi, A.M. Romero, C.V. Ragel, R.Z. LeGeros, J. Biomed. Mater. Res. 44 (1999) 416-421.

[32] P. Saravanapavan, J.R. Jones, R.S. Pryce, L.L. Hench, J. Biomed. Mater. Res. Part A 66A (2003) 110-119.

[33] H. Takadama, H.M. Kim, T. Kokubo, T. Nakamura, Chem. Mater. 13 (2001) 1108-1113.

[34] H.W. Yan, K. Zhang, C.F. Blanford, L.F. Francis, A. Stein, Chem. Mater. 13 (2001) 1374-1382.
[35] I. Izquierdo-Barba, A.J. Salinas, M. Vallet-Regi, J. Biomed. Mater. Res. 47 (1999) 243-250.

[36] J.Y. Kim, P.N. Kumta, J. Phys. Chem. B 102 (1998) 5744-5753.

[37] R. Hsu, J.Y. Kim, P.N. Kumta, T.P. Feist, Chem. Mater. 8 (1996) 107-113.

[38] R. Hsu, P.N. Kumta, T.P. Feist, J. Mater. Sci. 30 (1995) 3123-3129.

[39] L. Zhang, H. Eckert, J. Mater. Chem. 15 (2005) 1640-1653.

[40] C. Canevali, R. Scotti, A. Vedda, M. Mattoni, F. Morazzoni, L. Armelao, D. Barreca, G. Bottaro, Chem. Mater. 16 (2004) 315-320.

[41] P. Muralidharan, M. Venkateswarlu, N. Satyanarayana, Mater. Res. Bull. 39 (2004) 1753-1762.

[42] A.D. Irwin, J.S. Holmgren, J. Jonas, J. Non-Cryst. Solids 101 (1988) 249-254.

[43] A.D. Irwin, J.S. Holmgren, T.W. Zerda, J. Jonas, J. Non-Cryst. Solids 89 (1987) 191-205

[44] G.D. Soraru, N. Dallabona, C. Gervais, F. Babonneau, Chem. Mater. 11 (1999) 910-919. 